\title{
Polymer Light-Emitting Electrochemical Cells-Recent Advances and Future Trends
}

\author{
Jun $\mathrm{Gao}^{1 *}$ \\ ${ }^{1}$ Department of Physics, Engineering Physics and Astronomy, Queen's University, Kingston, \\ Ontario, K7L 3N6, Canada
}

\begin{abstract}
Polymer light-emitting electrochemical cells (PLECs) are electroluminescent devices whose operation involves both ionic and electronic charges. A key reaction in PLEC is the electrochemical doping of the light emitter, a luminescent polymer, which eventually leads to the formation of a light emitting p-n or p-i-n junction in the interior of the cell. This review opens with a general introduction to the operating mechanism of PLECs. This is followed by a summary of key advancements in the field in the last two years. The focus of the review is on the chemical mapping and optical probing of the PLEC doping process and junction structures. The results showcased in this review provide a coherent picture of the PLEC operating mechanism and point in new research directions in both device applications and fundamental sciences of mixed ionic/electronic polymer conductors.
\end{abstract}

*Email: jungao@queensu.ca 


\section{Introduction}

A light-emitting electrochemical cell (LEC) is a molecular electronic device developed alongside polymer and organic light-emitting diodes (PLEDs and OLEDs) for potential lighting and display applications. The term "electrochemical" implies the presence of ionic species by design. And electrochemical redox reactions involving both mobile ions and a light emitter are responsible for light emission from the cell. The light emitter in an LEC is invariably immobile and in direct contact with both electrodes. As such, LECs are solid-state electroluminescent (EL) devices and distinguished from liquid electrochemical cells wherein the light generated is typically electrochemiluminescent (ECL) in nature.[1,2]

The first LECs were polymer LECs or PLECs.[3,4] The active layer of a PLEC is typically a blend of a luminescent conjugated polymer as the electronic conductor and a polymer electrolyte as the ion conductor. LECs can be made with materials other than polymers.[5,6] This short review, however, concerns only PLECs and their key developments in the past two years. In particular, the focus is on the electrochemical and electronic structure of PLECs studied via various optical imaging and probing techniques. For information on other aspects of PLECs and other types of LECs, readers are urged to refer to recent reviews on the subject.[5,7,8]

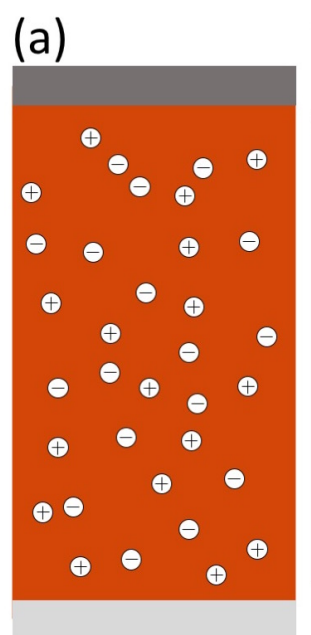

(b)

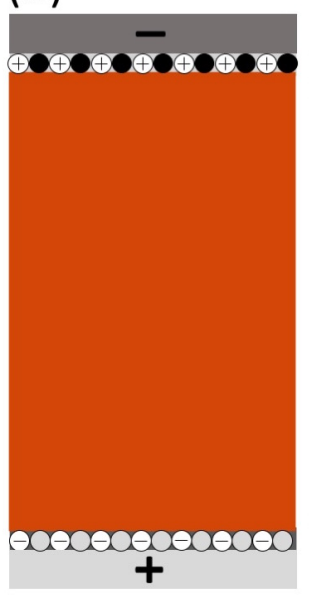

(c)

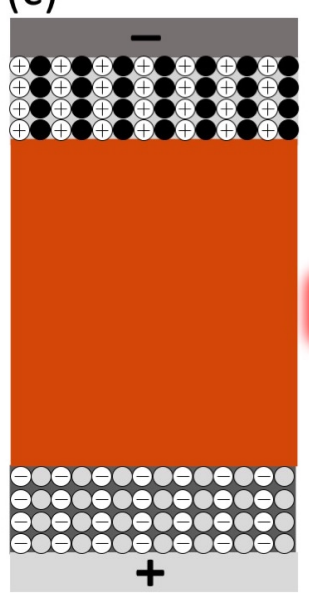

(d)

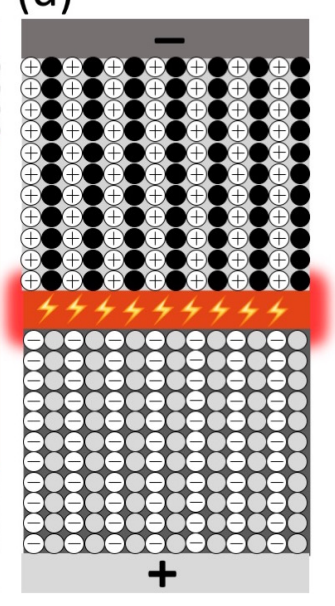

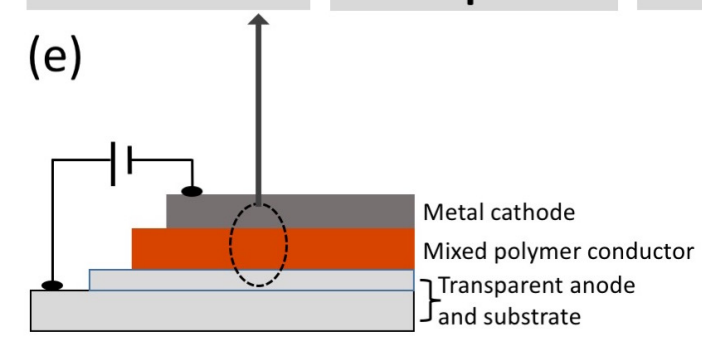

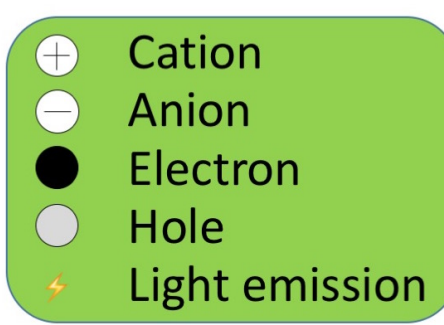


Figure 1. Schematic illustration of PLEC device structure and operation. (a) Pristine PLEC without any voltage bias; mobile ions are uniformly distributed throughout the active layer. (b) PLEC under an applied voltage bias; in situ electrochemical doping first takes place at the anode and cathode interfaces. (c) The expansion of the $\mathrm{p}$ - and $\mathrm{n}$-doped regions and the propagation of the doping fronts. (d) The formation of a light-emitting p-n junction; the PLEC is functional as a light-emitting device. (e) The schematic of a sandwich PLEC.

The presence of mobile ions (Figure 1 (a)) plays a central role in the PLEC operation. Upon the application of a sufficient DC voltage bias, injection of electrons and holes occur at the negative and positive electrodes, respectively, causing electrochemical doping of the luminescent polymer (Figure 1 (b). In PLECs, doping refers to the insertion of counterions, such as $\mathrm{CF}_{3} \mathrm{SO}_{3}{ }^{-}$ and $\mathrm{K}^{+}$, in the vicinity of an injected charge, which causes the semiconducting polymer to be doped, thus exhibiting vastly improved conductivity. The doping of the luminescent polymer poly (phenylene vinylene), PPV, is depicted by the following scheme.

$$
\begin{array}{ll}
\text { p-doping : } & (\mathrm{PV})_{n}+(\mathrm{nm}) \mathrm{CF}_{3} \mathrm{SO}_{3}^{-}-(\mathrm{nm}) e^{-} \leftrightarrow\left[\left(P V^{m+}\right)\left(\mathrm{CF}_{3} \mathrm{SO}_{3}^{-}\right)_{m}\right]_{n} \\
n-\text { doping }: & (\mathrm{PV})_{n}+(\mathrm{nm}) \mathrm{K}^{+}+(\mathrm{nm}) e^{-} \leftrightarrow\left[\left(P V^{m-}\right)\left(K^{+}\right)_{m}\right]_{n}
\end{array}
$$

Once the doping is initiated, the doping fronts move away from the electrode interfaces, leaving behind a doped region, as shown in Figure 1 (c). The presence of a doping front is necessitated by the higher conductivity of the doped region and can be numerically modeled.[911] The p-and n-doped regions continue to expand under the applied voltage bias until they meet to form a p-n or p-i-n junction, as shown in Figure 1 (d). This opens up a pathway for a significant electronic current. Junction EL results when injected electrons and holes recombine radiatively in the junction region.

The PLEC operation mechanism described above, also known as the electrochemical doping (ECD) model, was proposed by the original authors of the work to account for the unique device characteristics of PLECs.[3,12] Vastly reduced bulk and contact resistance, brought on by the high ion concentration and subsequent in situ electrochemical doping, readily explains PLEC's insensitivity to electrode work function and active layer thickness.[13] PLECs can therefore be made with an air-stable cathode and a thicker, more robust active layer. These traits make PLECs an appealing alternative to PLEDs. The PLEC's insensitivity to electrode work function and active layer thickness also makes it possible to fabricate functional planar cells, where the two electrodes (often the same metal) contact the same top or bottom surface of the active layer, with 
some separation. The imaging of the original planar PLEC, fabricated on top of a pair of interdigitated gold electrodes with a gap size of $15 \mu \mathrm{m}$, offers the first visual evidence of a lightemitting p-n junction in an activated PLEC.[3] Later on, planar PLECs with a gap size of millimeters was demonstrated.[14,15] Extremely large planar PLECs have become an invaluable tool for the study of fundamental PLEC processes.[16-20] In Sections IV and V, time-lapse fluorescence imaging of large planar PLECs offer visual confirmation of the ECD model illustrated in Figure 1.

\section{New materials and performance records in PLECs}

In the past two years, PLEC research has advanced on many fronts. Device performance parameters such as peak luminance, efficiency and lifetime have all improved through better device and material engineering. By choosing the right barrier material, for example, an encapsulated PLEC built on a flexible substrate has been shown to be functional after a year in storage under ambient conditions.[21] PLECs have also been tested either continuously or intermittently, to extract an operational lifetime that can exceed 1,000 hours.[22-24] High performance electrolytes, based on star-branched oligomers, have been synthesized and applied to PLECs, leading to a record-high power conversion efficiency of $18.1 \mathrm{~lm} / \mathrm{W}$.[24] Figure 2 shows the turn-on kinetics and long-term stability of sandwich PLECs made with these highperformance electrolytes.

(a)
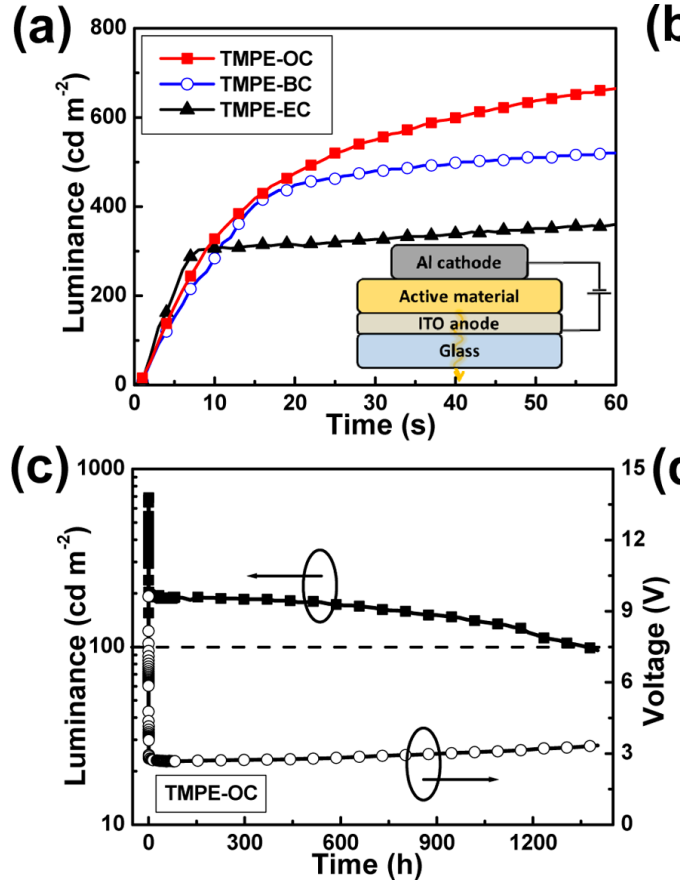

(b)
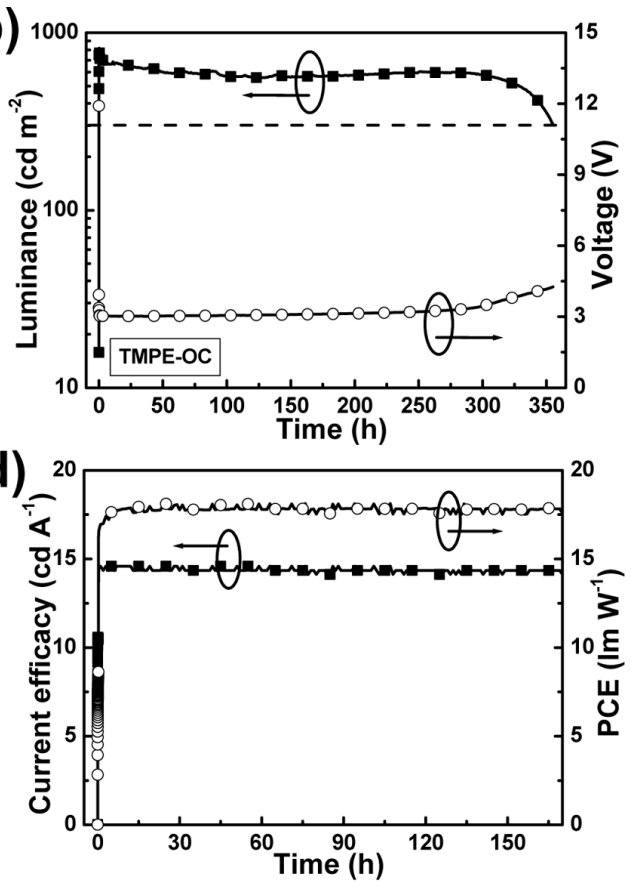
Figure 2. (a) Turn-on kinetics during the first min of operation and (b) the long-term stability of ITO/ \{SY + ion-transporter + LiCF3SO3 $3 / \mathrm{Al}$ sandwich-cell LECs, with the device structure disclosed in the inset of (a). The devices were driven by $\mathrm{j}=7.7 \mathrm{~mA} \mathrm{~cm}-2$. (c) The long-term stability of a TMPE-OC device driven by a prebias of $7.7 \mathrm{~mA} \mathrm{~cm}-2$ for $40 \mathrm{~min}$ and thereafter by $1.9 \mathrm{~mA} \mathrm{~cm}-2$. (d) The temporal evolution of the efficiency for a TMPE-OC device equipped with a light-outcoupling film. The device was driven by a prebias of $7.7 \mathrm{~mA} \mathrm{~cm}-2$ for $40 \mathrm{~min}$ and thereafter by $0.77 \mathrm{~mA} \mathrm{~cm}-2$. Reprinted with permission from (Mindemark, M.;Tang, S.;Wang, J.; Kalhovirta, N.; Brandell, D. and Edman, L., HighPerformance Light-Emitting Electrochemical Cells by Electrolyte Design. Chemistry of Materials 2016, 28 (8), 2618-2623). Copyright (2016) American Chemical Society.

The study of PLECs is in a large part motivated by their simple device structures and their potential as a low-cost alternative to existing or other emerging lighting technologies. Indeed, single-layer blue, white and near IR PLECs have been demonstrated with new emitters that are either donor- $\pi$-acceptor copolymers or donor/acceptor blends.[25-29] PLECs can also be driven from $\mathrm{AC}$ mains via an organic power converter and compatible with low-cost processing techniques.[30,31] The versatility of PLECs is further evidenced by the demonstration of stretchable, dual mode (electrochromic/emitting), biodegradable, or electrolyte layer mediated devices.[32-38] With a pulsed driving scheme, a peak current density in excess of 2,000 A/ $\mathrm{cm}^{2}$ has been realized in a planar PLEC. This record high current density, along with a direct doping charge measurement, again attest to the highly doped nature of functioning PLECs.[39,40]

\section{Time-resolved chemical mapping in planar PLECs}

The inherent complexity of a PLEC operation, which involves both ionic and electronic charges, has also produced fertile ground for the study of fundamental PLEC processes. The effect of salt anion on the performance of sandwich PLECs has been investigated.[41]The change in the refractive index of a LEC polymer has been measured as the polymer underwent controlled electrochemical doping. The results shed light on why the p- and n-doped polymer has different optical properties. [42] According to the ECD model, anions are mainly found in the pdoped region serving as counter ions for the oxidized luminescent polymer. This has been confirmed by a FTIR spectroscopic imaging study conducted on a planar PLEC.[43] Figure 3 shows side-by-side comparisons of the spectra and chemical intensity profiles of the PLEC before and after a $4 \mathrm{~V}$ bias has been applied. The triflate anions are traced by the $\mathrm{SO}_{3}{ }^{-}$vibration bands, and the oxidized MEH-PPV is identified by the $\mathrm{C}-\mathrm{C}$ and ring stretching bands. The profiles clearly show that the anions are homogenously distributed when the PLEC is in its pristine state. After being biased at $4 \mathrm{~V}$ for an hour however, a much higher density of anions is found on the anode side where the luminescent polymer MEH-PPV has been oxidized. This 
study provides the first evidence of large-scale ion motion in a PLEC and complements the early profiling of sandwich PLECs by secondary ion mass spectrometry.[44,45] Time-resolved intensity mapping provides further support to the ECD model of PLEC operation.

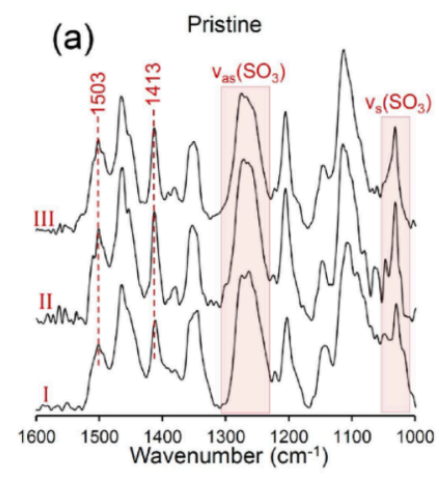

(b)

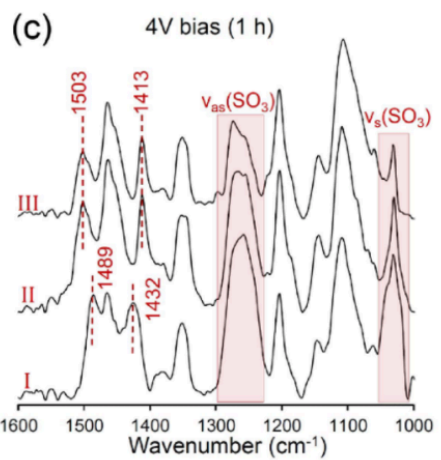

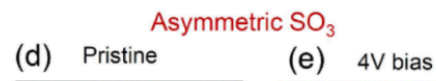

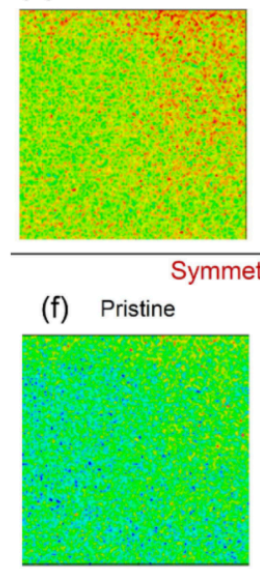

(e) $4 \mathrm{~V}$ bias

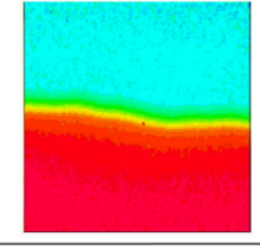

(g) $4 \mathrm{~V}$ bias

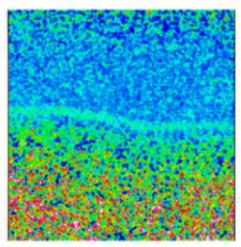

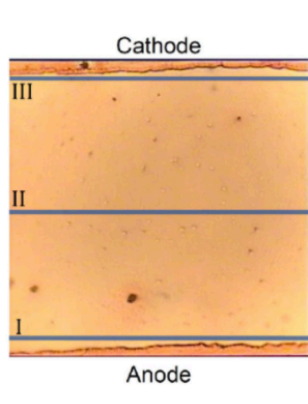

MEH-PPV C-C vibration (h) Pristine

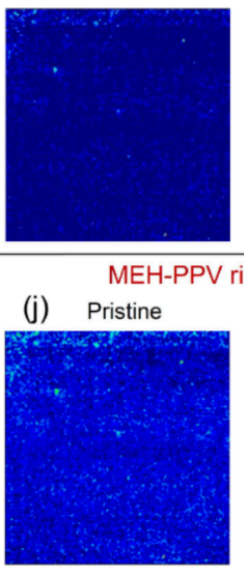

(i) $4 \mathrm{~V}$ bias
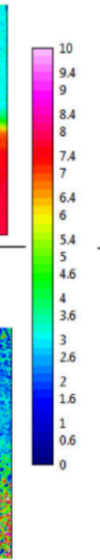

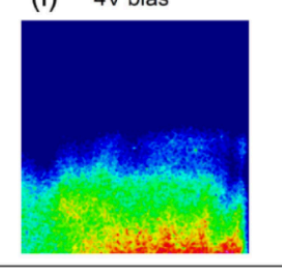

(k) $4 \mathrm{~V}$ bias

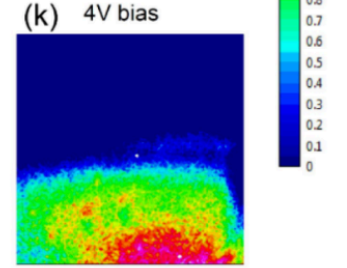

Figure 3. FTIR line-averaged spectra of (a) the pristine sample and (c) the sample under $4 \mathrm{~V}$ applied bias after $1 \mathrm{~h}$, obtained from lines I, II, and III in the reflection image (b) of the LEC device. The chemical intensity maps $(\mathrm{d}-\mathrm{k})$ were obtained over the same field of view as panel $\mathrm{b}$ and show integrated intensities over specific bands. For each pair of images, the left was obtained under zero bias (pristine sample), and the right was obtained under an applied bias. ( $\mathrm{d}$ and e) Asymmetric and (f and g) symmetric $\mathrm{SO}_{3}{ }^{-}$vibration of the triflate anion; (h and i) $\mathrm{C}-\mathrm{C}$ stretching and ( $\mathrm{j}$ and $\mathrm{k}$ ) ring stretching of $\mathrm{MEH}-\mathrm{PPV}$. The bands are as follows: asymmetric $\mathrm{SO}_{3}^{-}, 1290-1218 \mathrm{~cm}^{-1}$; symmetric $\mathrm{SO}_{3}^{-}, 1055-1007 \mathrm{~cm}^{-1}$; $\mathrm{C}-\mathrm{C}$ stretch, $1441-1406 \mathrm{~cm}^{-1}$; ring vibration, $1503-1475 \mathrm{~cm}^{-1}$. The field of view is $300 \times 300 \mu \mathrm{m}^{2}$ in all images. Reprinted (adapted) with permission from (Jafari, M. J.; Liu, J.; Engquist, I.; Ederth, T., TimeResolved Chemical Mapping in Light-Emitting Electrochemical Cells. Acs Applied Materials \& Interfaces 2017, 9 (3), 2747-2757). Copyright (2017) American Chemical Society. 


\section{Scanning OBIC and PL imaging of a frozen PLEC junction}

Since the PLEC is essentially a polymer p-n junction once activated, it is important to know the spatial extent of the junction depletion region. The optical beam induced current (OBIC) technique is well suited to extract this important junction parameter and has been applied to planar PLECs for this purpose.[46-49] In OBIC probing, a focused light beam is scanned across the planar cell and the resulting photocurrent is recorded. When photo-excitation occurs in the vicinity of the depletion region, a photocurrent is generated whose magnitude correlates with the local built-in electric field. In neutral p- or n-doped regions, by contrast, a null OBIC signal is expected due to the absence of any built-in field that can sweep the photogenerated charge carriers before they recombine. To perform an OBIC scan on a PLEC, a static doping profile and a straight junction are required to avoid any interference from the motion of ions or artificial broadening of the signal profile. In addition, the optical beam must be narrow and have a known profile. Third, the activated PLEC must have adequate conductivity to allow the minute photocurrent to be resolved against any background noise current. These conditions have been met in a recent study employing a focused laser beam and a large, frozen-junction planar PLEC.[50,51] Moreover, the scan can simultaneously record the photoluminescence (PL) intensity across the scan path.

(a)

(b)

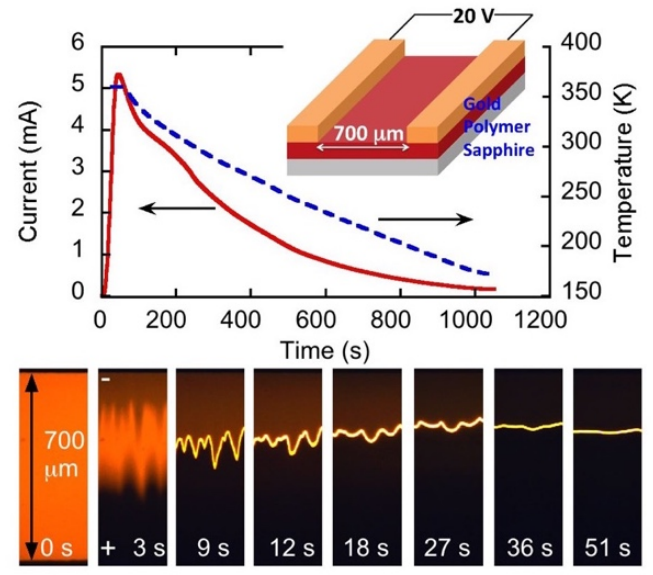

(c)

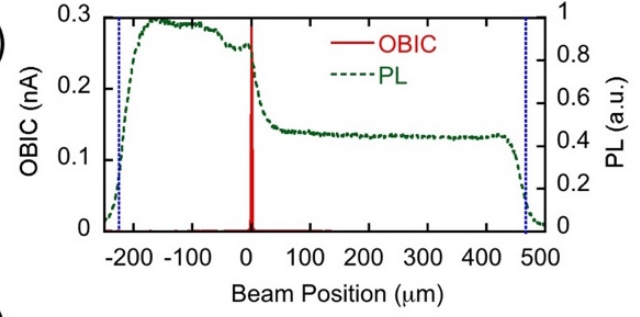

(d)

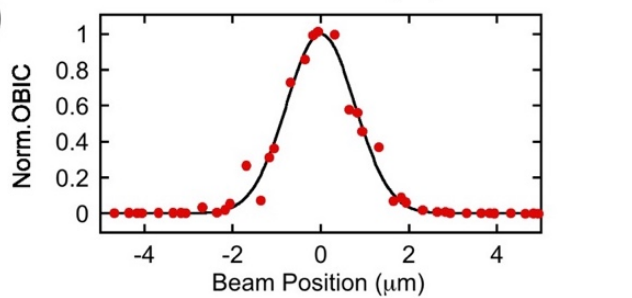

Figure 4. Scanning OBIC and PL imaging of a frozen planar PLEC. (a) Time evolution of cell current and cell temperature during the activation process. A DC voltage bias of $20 \mathrm{~V}$ is applied. The inset shows the schematic of the planar PLEC. (b) Time-lapse fluorescence images of the planar LEC during the activation process. Only a section of the entire cell is shown. (c) Electrode-to-electrode OBIC and PL 
scans. The cathode is located at $-230 \mu \mathrm{m}$ and the anode is located at $470 \mu \mathrm{m}$. (d) OBIC scan data of four scans along the same path and a Gaussian fit to the data near the OBIC peak. Reprinted (adapted) with permission from (AlTal, F. and Gao, J., High resolution scanning optical imaging of a frozen polymer p-n junction. Journal of Applied Physics 2016, 120 (11), 115501). Copyright (2016) American Institute of Physics.

Figure 4 (a) shows the schematic of the $700 \mu \mathrm{m}$ planar PLEC that has been activated and subsequently scanned. A $20 \mathrm{~V}$ constant bias voltage was applied to activate the PLEC, which was heated to $360 \mathrm{~K}$. Under these conditions, the cell current rapidly increased to over $5 \mathrm{~mA}$ in about $50 \mathrm{~s}$ due to doping. The PLEC was subsequently cooled to $170 \mathrm{~K}$ to freeze the doping profile and the light-emitting junction formed. Figure 4 (b) shows the time-lapse fluorescence images of the PLEC before cooling. The orange PL of the light-emitting polymer MEH-PPV has been significantly quenched, revealing the doped regions. A light-emitting p-n junction is formed when the p- and n-doping fronts make contact. Figure 4 (c) shows the OBIC and PL profiles of a full (electrode-to-electrode) scan. The PL profile consists of an n-doped region to the left of higher overall PL and a darker, p-doped region to the right of the OBIC peak. A fairly broad $(\sim 30 \mu \mathrm{m})$ transition zone is also detected between the two regions. The OBIC peak, by contrast, is extremely narrow. As expected, the OBIC signal is only detected in the junction region at the edge of the PL transition zone. Figure 4 (d) provides an expanded view of the OBIC profile that includes all data points from a total of four scans along the same path. The data are fitted to a Gaussian function with a $1 / \mathrm{e}^{2}$ width (defined as the width where the intensity has fallen to $1 / \mathrm{e}^{2}=$ 0.135 times the peak value) of $3.1 \mu \mathrm{m}$, greater than the width of Gaussian excitation beam of 1.9 $\mu \mathrm{m}$. In all, an average junction width of $1.5 \mu \mathrm{m}$ is determined from 18 scans along seven paths after deconvolution to remove the width of the excitation beam. These results illustrate the first time the depletion width of a frozen PLEC p-n junction has been resolved. The junction width is only $0.21 \%$ of the interelectrode gap, which is the lowest value measured among all PLECs.

\section{PLECs with bipolar electrodes}

Although called an electrochemical cell, PLECs are mainly studied as an alternative to PLEDs using the standard techniques and terminologies of organic and conventional semiconductor devices. Recently, the PLEC research has crossed into the field of bipolar electrochemistry, which has many applications but typically involves a liquid electrolyte.[52-56] Up to this point, it has been shown that the PLEC is a simple electrochemical cell terminated by two wired metal 
electrodes, where the oxidation and reduction half reactions are initiated. The introduction of a floating conductor, in the interior of the PLEC, creates a bipolar electrode, or BPE that is capable of driving both reduction and oxidation reactions even though it is not directly connected to a power source.[57] This scenario is shown in Figure 5.
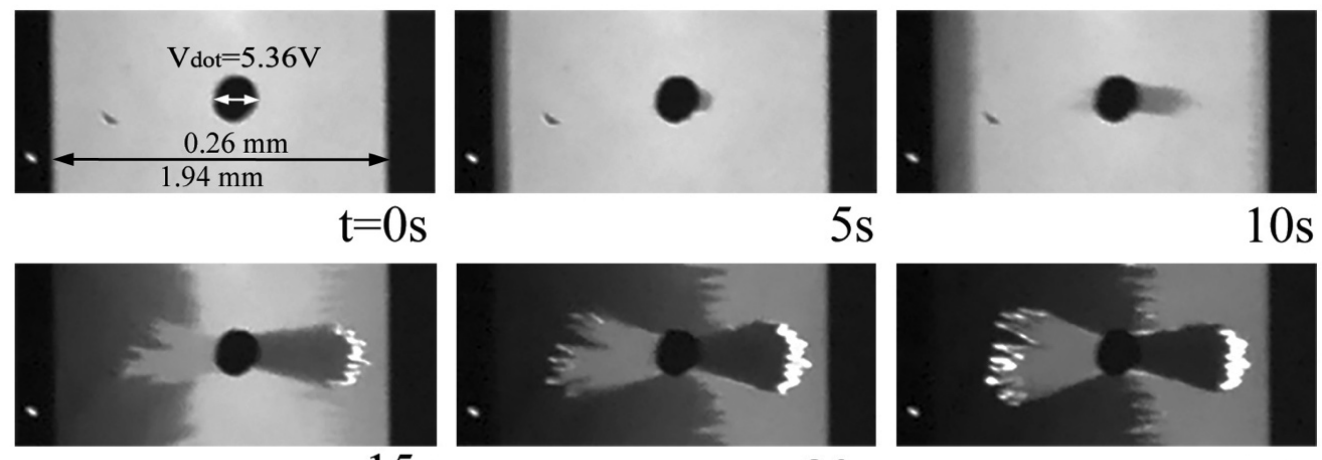

$5 \mathrm{~s}$
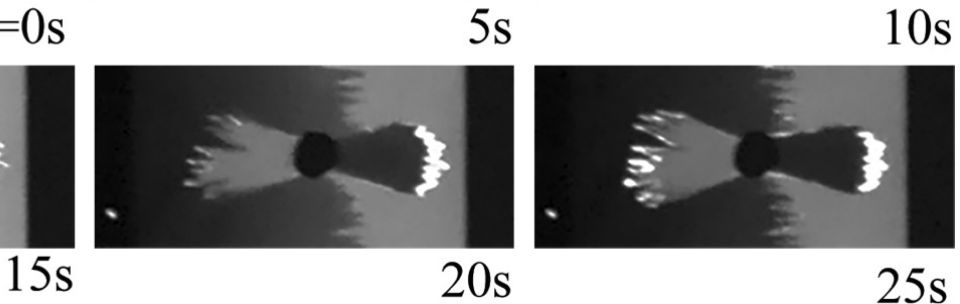

$25 \mathrm{~s}$
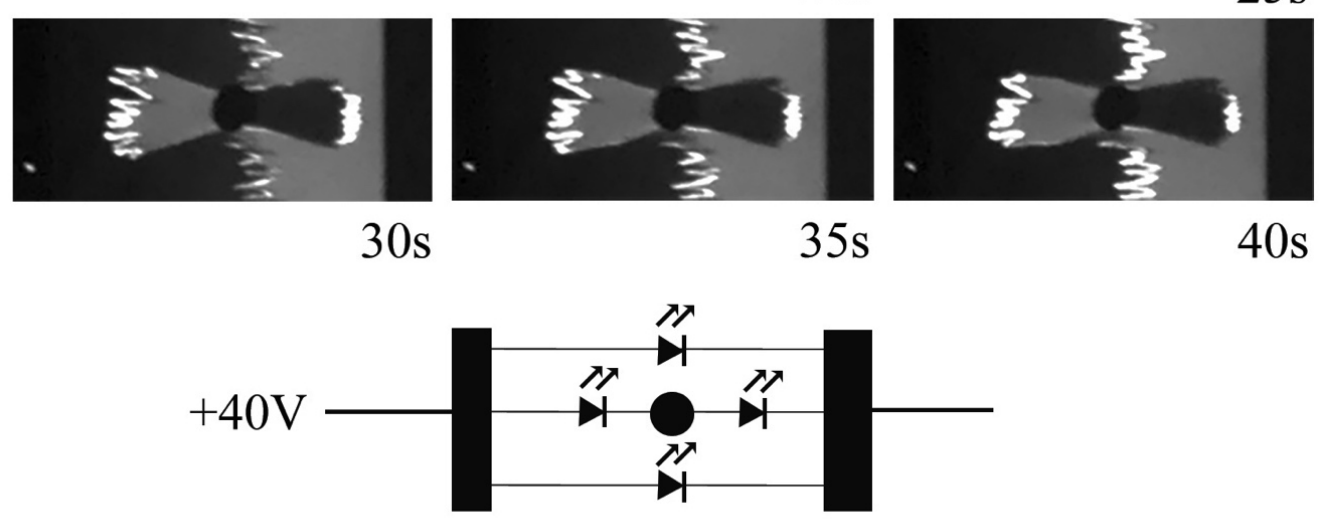

Figure 5. Time-lapse fluorescence images of a $1.94 \mathrm{~mm}$ planar cell consisting of one gold and one aluminum driving electrode, and a single aluminum disc BPE. The top part of the figure shows the cropped images of the cell around the BPE. The images were batch processed and uniformly enhanced in Photoshop. The cell was heated to $350 \mathrm{~K}$ and a $40 \mathrm{~V}$ bias was applied across the driving electrodes. The lower part of the graph shows the equivalent circuit of the cell when fully emitting. Reprinted (adapted) with permission from (Chen, S., Wantz, G., Bouffier, L., and Gao, J., Solid-state bipolar electrochemistry-polymer light-emitting electrochemical cells. ChemElectroChem 2016, 3, 392-398). Copyright (2016) John Wiley and Sons Inc.

A single aluminum disc BPE of $0.26 \mathrm{~mm}$ in diameter is deposited on top of the active layer of a $1.94 \mathrm{~mm}$ planar PLEC. Electrochemical p- and n-doping, manifested as PL quenching, are not only induced by the driving electrodes, but also by the aluminum disc BPE. The doping reactions occur preferentially at the opposite extremities of the BPE where the potential difference 
between the BPE and the PLEC film is the largest. The various doping fronts eventually meet to form four separate light-emitting p-n junctions, instead of the usual one. In PLECs with a linear array of BPEs, $\mathrm{p}$ - and $\mathrm{n}$-doping originated from neighboring BPEs can interact to form multiple light-emitting p-n junctions in series.[58] With dispersed micro-BPEs, thousands of tiny lightemitting p-n junctions are formed within the bulk of the PLEC layer, creating a bulk homojunction PLEC.[59,60] A bulk homojunction PLEC, which is an analog of bulk ECL generation in a liquid cell,[61] exhibits vastly improved light output and giant open-circuit voltage when operated as a photovoltaic cell in the frozen-junction mode. BPE and bipolar electrochemistry, therefore, offer an elegant solution to the problem of narrow junction in PLECs. PLECs, in return, offer a brand new platform to conduct bipolar electrochemistry research in solid state. Solid-state bipolar electrochemistry complements conventional liquid electrolyte based bipolar electrochemical research and offers advantages such as simplicity and versatility in cell design and characterization. The solid state nature of the mixed ionic/electronic conductor, for example, allows for the demonstration of several new types of bipolar electrodes that are otherwise impossible to realize in a liquid cell. [62]

\section{Conclusions and outlook}

PLECs are unique among organic photonic devices. The presence of mobile ions and the important role of doping and junction formation in PLEC operation distinguish PLECs from purely electronic PLEDs and OLEDs. PLECs exhibit highly desirable characteristics and have simple device structures. For practical applications, however, PLECs lag behind PLEDs and OLEDs in both operational lifetime and efficiency. The record lifetime and efficiency shown in Figure 2 has been achieved at relatively low luminance and current levels. At high luminance levels, PLECs suffer from severe efficiency roll-off due to increased level of doping that quenches the fluorescence of the polymer.[63] High intensity operation is also detrimental to the lifetime of PLECs.[22,64] An intermittent testing scheme, however, revealed that the fast luminance decay observed in PLEC stress test was in part caused by the reversible doping process and therefore largely recoverable. $[65,66]$ This discovery suggests that the operational lifetime of PLECs could have been vastly underestimated. The ultimate solution to the fundamental tradeoff between efficiency and emission intensity [63] lies with frozen-junction LECs, in which all doping or side reactions involving mobile ions cease after junction formation.[67,68]. More research, however, is needed to realize frozen-junction LECs that have 
sufficient shelf stability when stored at room temperature. The current record of about 1200 hours is realized by removing the ion-transporting polymer from the PLEC blends altogether. [69]. BPEs, especially their dispersed form, offer additional opportunities for efficiency enhancement by increasing the number of emitting junctions.[59,60] Fundamental research is also needed to better understand the complex doping processes and the electronic structures of the PLEC junction. In particular, we need to experimentally answer the question-how does the junction width scale with the separation between the driving electrodes or BPEs? Here, extremely large planar PLECs are a valuable and versatile tool due to easy access, via both electrical and optical probes, to the active layer. The study of PLECs, both as a viable lightemitting device as well as a visual model system could also be of potential interest to the wider electrochemical device community.

\section{ACKNOWLEDGMENT}

The study at Queen's University was supported by the Natural Sciences and Engineering Research Council of Canada (NSERC).

\section{References}

Papers of particular interest, published within the period of review, have been highlighted as:

- of special interest

•• of outstanding interest.

1. Kim JY, Cheon S, Lee H, Oh JY, Lee JI, Ryu H, Kim YH, Hwang CS: Smart approach to liquid electrolyte-based multi-colored electrochemiluminescence for lighting applications. Journal of Materials Chemistry C 2017, 5:4214-4218.

2. Hesari M, Ding ZF: Review-Electrogenerated Chemiluminescence: Light Years Ahead. Journal of the Electrochemical Society 2016, 163:H3116-H3131.

3. Pei QB, Yu G, Zhang C, Yang Y, Heeger AJ: Polymer Light-Emitting Electrochemical-Cells. Science 1995, 269:1086-1088. ** First journal report of PLECs

4. Pei $Q$, Yang $Y$, Yu G, Zhang C, Heeger AJ: Polymer Light-Emitting Electrochemical Cells: In Situ Formation of a Light-Emitting $\mathbf{p}-\mathrm{n}$ Junction. Journal of the American Chemical Society 1996, 118:3922-3929. ** A classic PLEC paper on the ECD model and some pioneering experimental characterization work 
5. Fresta $E$, Costa RD: Beyond traditional light-emitting electrochemical cells - a review of new device designs and emitters. Journal of Materials Chemistry C 2017, 5:5643-5675.

6. Meier SB, Tordera D, Pertegas A, Roldan-Carmona C, Orti E, Bolink HJ: Light-emitting electrochemical cells: recent progress and future prospects. Materials Today 2014, 17:217-223.

7. Tang S, Edman L: Light-Emitting Electrochemical Cells: A Review on Recent Progress. Topics in Current Chemistry 2016, 374.

8. Mindemark J, Edman L: Illuminating the electrolyte in light-emitting electrochemical cells. Journal of Materials Chemistry C 2016, 4:420-432. * A paper on the importance of electrolyte design in PLECs

9. Robinson ND, Shin J-H, Berggren M, Edman L: Doping front propagation in light-emitting electrochemical cells. Physical Review B 2006, 74:155210.

10. Bychkov V, Matyba P, Akkerman V, Modestov M, Valiev D, Brodin G, Law CK, Marklund M, Edman L: Speedup of Doping Fronts in Organic Semiconductors through Plasma Instability. Physical Review Letters 2011, 107:016103.

11. Modestov M, Bychkov V, Brodin G, Valiev D, Marklund M, Matyba P, Edman L: Model of the electrochemical conversion of an undoped organic semiconductor film to a doped conductor film. Physical Review B 2010, 81:081203.

12. Pei $Q$, Heeger AJ: Operating mechanism of light-emitting electrochemical cells. Nature Materials 2008, 7:167-167.

13. Gozzi G, Cagnani LD, Faria RM, Santos LF: Electrical properties of electrochemically doped organic semiconductors using light-emitting electrochemical cells. Journal of Solid State Electrochemistry 2016, 20:2127-2133.

14. Gao J, Dane J: Planar polymer light-emitting electrochemical cells with extremely large interelectrode spacing. Applied Physics Letters 2003, 83:3027. ** First report of extremely large planar PLECs

15. Gao J, Dane J: Visualization of electrochemical doping and light-emitting junction formation in conjugated polymer films. Applied Physics Letters 2004, 84:2778-2780.

16. Dane J, Tracy C, Gao J: Direct observation of a frozen junction in polymer light-emitting electrochemical cells. Applied Physics Letters 2005, 86:153509.

17. Alem S, Gao J: The effect of annealing/quenching on the performance of polymer lightemitting electrochemical cells. Organic Electronics 2008, 9:347-354.

18. Hohertz D, Gao J: How Electrode Work Function Affects Doping and Electroluminescence of Polymer Light-Emitting Electrochemical Cells. Advanced Materials 2008, 20:32983302.

19. Hu YF, Gao J: Direct Imaging and Probing of the p-n Junction in a Planar Polymer LightEmitting Electrochemical Cell. Journal of the American Chemical Society 2011, 133:2227-2231. * Electric potential and conductivity mapping of the largest frozenjunction planar PLEC

20. Hu YF, Gao J: Cationic effects in polymer light-emitting electrochemical cells. Applied Physics Letters 2006, 89:253514.

21. Asadpoordarvish A, Sandstrom A, Edman L: A Flexible Encapsulation Structure for AmbientAir Operation of Light-Emitting Electrochemical Cells. Advanced Engineering Materials 2016, 18:105-110. 
22. Jang JH, Kim LH, Jeong YJ, Kim K, An TK, Kim SH, Park CE: Accelerated lifetime test based on general electrical principles for light-emitting electrochemical cells. Organic Electronics 2016, 34:50-56.

23. AlTal F, Gao J: Long-term testing of polymer light-emitting electrochemical cells: Reversible doping and black spots. Organic Electronics 2015, 18:1-7.

24. Mindemark J, Tang S, Wang J, Kaihovirta N, Brandell D, Edman L: High-Performance LightEmitting Electrochemical Cells by Electrolyte Design. Chemistry of Materials 2016, 28:2618-2623.* A report on long-lasting, high-efficiency sandwich PLECs by electrolyte design

25. Geng ZM, Sato G, Marumoto K, Kijima M: D-pi-A Polysulfones for Blue Electroluminescence. Journal of Polymer Science Part a-Polymer Chemistry 2016, 54:3454-3461.

26. Nishikitani Y, Takizawa D, Nishide H, Uchida S, Nishimura S: White Polymer Light-Emitting Electrochemical Cells Fabricated Using Energy Donor and Acceptor Fluorescent piConjugated Polymers Based on Concepts of Band-Structure Engineering. Journal of Physical Chemistry C 2015, 119:28701-28710.

27. Nishikitani Y, Takeuchi H, Nishide H, Uchida S, Yazaki S, Nishimura S: White polymer lightemitting electrochemical cells using emission from exciplexes with long intermolecular distances formed between polyfluorene and pi-conjugated amine molecules. Journal of Applied Physics 2015, 118.

28. Tang S, Buchholz HA, Edman L: White Light from a Light-Emitting Electrochemical Cell: Controlling the Energy-Transfer in a Conjugated Polymer/Triplet-Emitter Blend. Acs Applied Materials \& Interfaces 2015, 7:25955-25960.

29. Tang S, Murto P, Xu X, Larsen C, Wang E, Edman L: Intense and Stable Near-Infrared Emission from Light-Emitting Electrochemical Cells Comprising a Metal-Free Indacenodithieno[3,2-b]thiophene-Based Copolymer as the Single Emitter. Chemistry of Materials 2017, 29:7750-7759.

30. Larsen C, Forchheimer R, Edman L, Tu DY: Design, fabrication and application of organic power converters: Driving light-emitting electrochemical cells from the AC mains. Organic Electronics 2017, 45:57-64.

31. Sato K, Uchida S, Toriyama S, Nishimura S, Oyaizu K, Nishide H, Nishikitani Y: Low-Cost, Organic Light-Emitting Electrochemical Cells with Mass-Producible Nanoimprinted Substrates Made Using Roll-to-Roll Methods. Advanced Materials Technologies 2017, 2.

32. Gao H, Chen S, Liang JJ, Pei QB: Elastomeric Light Emitting Polymer Enhanced by Interpenetrating Networks. Acs Applied Materials \& Interfaces 2016, 8:32504-32511.

33. Tsuneyasu S, Jin L, Nakamura K, Kobayashi N: An electrochemically-driven dual-mode display device with both reflective and emissive modes using poly(pphenylenevinylene) derivatives. Japanese Journal of Applied Physics 2016, 55.

34. Pu J, Fujimoto T, Ohasi Y, Kimura S, Chen CH, Li LJ, Sakanoue T, Takenobu T: A Versatile and Simple Approach to Generate Light Emission in Semiconductors Mediated by Electric Double Layers. Advanced Materials 2017, 29.

35. Luan XN, Liu J, Pei QB, Bazan GC, Li HP: Electrolyte Gated Polymer Light-Emitting Transistor. Advanced Materials Technologies 2016, 1. 
36. Zimmermann J, Jurgensen N, Morfa AJ, Wang BH, Tekoglu S, Hernandez-Sosa G: Poly(lacticco-glycolic acid) (PLGA) as lon-Conducting Polymer for Biodegradable Light-Emitting Electrochemical Cells. Acs Sustainable Chemistry \& Engineering 2016, 4:7050-7055.

37. Jurgensen N, Zimmermann J, Morfa AJ, Hernandez-Sosa G: Biodegradable Polycaprolactone as Ion Solvating Polymer for Solution-Processed Light-Emitting Electrochemical Cells. Scientific Reports 2016, 6.

38. Lindh EM, Sandstrom A, Andersson MR, Edman L: Luminescent line art by direct-write patterning. Light-Science \& Applications 2016, 5.

39. Sakanoue T, Li JP, Tanaka H, Ito R, Ono S, Kuroda S, Takenobu T: High Current Injection into Dynamic p-n Homojunction in Polymer Light-Emitting Electrochemical Cells. Advanced Materials 2017, 29. * Record current density realized in a planar PLEC

40. AlTal F, Gao J: Charging and discharging of a planar polymer light-emitting electrochemical cell. Electrochimica Acta 2016, 220:529-535.

41. Chee KJ, Kumar V, Nguyen CV, Wang JX, Lee PS: Polymer Light-Emitting Electrochemical Cell Blends Based on Selection of Lithium Salts, LiX X = Trifluoromethanesulfonate, Hexafluorophosphate, and Bis(trifluoromethylsulfonyl)imide with Low Turn-On Voltage. Journal of Physical Chemistry C 2016, 120:11324-11330.

42. Lanz T, Lindh EM, Edman L: On the asymmetric evolution of the optical properties of a conjugated polymer during electrochemical p- and n-type doping. Journal of Materials Chemistry C 2017, 5:4706-4715.

43. Jafari MJ, Liu J, Engquist I, Ederth T: Time-Resolved Chemical Mapping in Light-Emitting Electrochemical Cells. Acs Applied Materials \& Interfaces 2017, 9:2747-2757. ** Timelapsed ion profiling in a planar PLEC using FTIR imaging

44. Toshner SB, Zhu Z, Kosilkin IV, Leger JM: Characterization of Ion Profiles in Light-Emitting Electrochemical Cells by Secondary Ion Mass Spectrometry. ACS Applied Materials \& Interfaces 2012, 4:1149-1153.

45. Shoji TD, Zhu Z, Leger JM: Characterizing Ion Profiles in Dynamic Junction Light-Emitting Electrochemical Cells. ACS Applied Materials \& Interfaces 2013, 5:11509-11514.

46. Dick DJ, Heeger AJ, Yang Y, Pei QB: Imaging the structure of the p-n junction in polymer light-emitting electrochemical cells. Advanced Materials 1996, 8:985-987.

47. Hu Y, Dorin B, Teng F, Gao J: Mapping the built-in electric field in polymer light-emitting electrochemical cells. Organic Electronics 2012, 13:361-365.

48. Inayeh A, Dorin B, Gao J: Scanning photocurrent and photoluminescence imaging of a frozen polymer p-n junction. Applied Physics Letters 2012, 101:253305.

49. AlTal F, Gao J: Scanning photocurrent and PL imaging of a frozen polymer $\mathbf{p}-\mathbf{i}-\mathbf{n}$ junction. physica status solidi (RRL) - Rapid Research Letters 2015, 9:77-81.

50. AlTal F, Gao J: High resolution scanning optical imaging of a frozen polymer p-n junction. Journal of Applied Physics 2016, 120. * The depletion width of a frozen PLEC $p-n$ junction is resolved for the first time

51. Altal F, Gao J: High resolution scanning optical imaging of a frozen planar polymer lightemitting electrochemical cell: an experimental and modelling study. Science ChinaChemistry 2017, 60:497-503.

52. Kuhn A, Crooks RM, Inagi S: A Compelling Case for Bipolar Electrochemistry. Chemelectrochem 2016, 3:351-352. 
53. Crooks RM: Principles of Bipolar Electrochemistry. Chemelectrochem 2016, 3:357-359.

54. Loget G, Zigah D, Bouffier L, Sojic N, Kuhn A: Bipolar Electrochemistry: From Materials

Science to Motion and Beyond. Accounts of Chemical Research 2013, 46:2513-2523.

55. Fosdick SE, Knust KN, Scida K, Crooks RM: Bipolar Electrochemistry. Angewandte ChemieInternational Edition 2013, 52:10438-10456.

56. Koefoed L, Pedersen SU, Daasbjerg K: Bipolar electrochemistry-A wireless approach for eletrode reactions. Current opinion in Electrochemistry 2017, 2:13-17.

57. Chen SL, Wantz G, Bouffier L, Gao J: Solid-State Bipolar Electrochemistry: Polymer-Based Light-Emitting Electrochemical Cells. Chemelectrochem 2016, 3:392-398. * First paper on solid-state bipolar electrochemistry realized in a planar PLEC

58. Gao J, Chen S, AlTal F, Hu S, Wantz G, Bouffier L: Bipolar Electrode Array Embedded in a Polymer Light-Emitting Electrochemical Cell. Acs Applied Materials \& Interfaces 2017, 9:32405-32410.

59. Tracy C, Gao J: Polymer bulk homojunction photonic devices. Applied Physics Letters 2005, 87:143502.

60. Tracy C, Gao J: Polymer bulk homojunction light-emitting electrochemical cells. Journal of Applied Physics 2006, 100:104503.

61. Sentic M, Arbault S, Bouffier L, Manojlovic D, Kuhn A, Sojic N: 3D electrogenerated chemiluminescence: from surface-confined reactions to bulk emission. Chemical Science 2015, 6:4433-4437.

62. Hu SY, Chi X, Chen SL, AITal F, Gao J: Visualizing the Bipolar Electrochemistry of Electrochemically Doped Luminescent Conjugated Polymers. Journal of Physical Chemistry C 2017, 121:8409-8415.

63. van Reenen S, Janssen RAJ, Kemerink M: Fundamental Tradeoff between Emission Intensity and Efficiency in Light-Emitting Electrochemical Cells. Advanced Functional Materials 2015, 25:3066-3073.

64. Li XY, Gao J, Liu GJ: Thickness dependent device characteristics of sandwich polymer lightemitting electrochemical cell. Organic Electronics 2013, 14:1441-1446.

65. Li XY, Gao J, Liu GJ: Reversible luminance decay in polymer light-emitting electrochemical cells. Applied Physics Letters 2013, 102:223303.

66. Li X, AlTal F, Liu G, Gao J: Long-term, intermittent testing of sandwich polymer lightemitting electrochemical cells. Applied Physics Letters 2013, 103:243304.

67. Gao J, Yu G, Heeger AJ: Polymer light-emitting electrochemical cells with frozen p-i-n junction. Applied Physics Letters 1997, 71:1293-1295.

68. Gao J, Li Y, Yu G, Heeger AJ: Polymer light-emitting electrochemical cells with frozen junctions. Journal of Applied Physics 1999, 86:4594.

69. Gautier B, Wu XM, Altal F, Chen SL, Gao J: Reverse bias activation of salt-doped polymer light-emitting devices. Organic Electronics 2016, 28:47-52. 